\title{
Twenty Years of Knudsen Effusion Mass Spectrometry: Studies Performed in the Period 1990-2010
}

\author{
Miroslaw Miller ${ }^{1,2, *}$ and Kamila Armatys ${ }^{3}$ \\ ${ }^{1}$ Wroclaw University of Technology, Faculty of Chemistry, Wyb. St. Wyspiańskiego 27, 50370 Wroclaw, Poland \\ ${ }^{2}$ Wrockaw Research Centre EIT+ Ltd, Stablowicka 147/149, 54-066 Wrockaw, Poland \\ ${ }^{3}$ Institute of Non Metallic Materials, Clausthal University of Technology, Zehntnerstraße 2a, 38678 Clausthal- \\ Zellerfeld, Germany
}

\begin{abstract}
Investigations carried out by Knudsen effusion mass spectrometry on metals, alloys, oxides, and fullerene systems in the period 1990-2010 are reviewed in the present paper. 362 original papers were published in this period by ca. 45 research groups thereby showing still large activity in this unique area. The fundamentals and recent developments of the method are briefly reported. Data to the systems studied, temperature ranges, vapour species identified in the equilibrium vapours and thermodynamic properties obtained in the study are reported. Important features of these studies are briefly discussed as well.

Most of the vaporization studies by Knudsen effusion mass spectrometry carried out on alloys, oxides and fullerenes aimed at the determination of thermodynamic data of gaseous species and condensed phases. Many of the studied materials are of practical importance for modern technologies. The investigations should give information on thermal stability, volatility under different conditions (temperature, oxygen partial pressure, and gaseous impurities), oxidation resistance, reactivity etc.
\end{abstract}

Keywords: Review, Knudsen Effusion Mass Spectrometry (KEMS), thermochemistry, high temperature, vaporisation, alloy, metal oxide, fullerene.

\section{INTRODUCTION}

The Knudsen effusion method for the vapour-pressure determination was developed by Martin Knudsen in the early 1900s [1]. Studying the effusion through the near-ideal round and cylindrical orifices and using the kinetic theory of gases, he found that too much sample effused through the orifice when the pressures of the effusing gas was high. He correlated these results with the mean-free path for the gaseous molecules and found that the orifice transmission probability increased when the ratio of mean-free path length to the orifice diameter was less then 10 . This is used as a criterion for the distinction between molecular flow and the hydrodynamic flow. Thus, the Knudsen effusion technique is spoken about when molecular flow takes place and effusing species are in equilibrium with condensed phases in the Knudsen cell.

For the first time mass spectrometry with the Knudsen effusion method was applied in 1948 by Ionov [2] to study vaporization of alkali metal halides. This study was followed by the investigations of Chupka and Inghram [3] as well as by Honig [4] to study the free evaporation of carbon. Since that time, Knudsen effusion mass spectrometry, with its

*Address correspondence to this author at the Wroclaw University of Technology, Faculty of Chemistry, Wyb. St. Wyspiańskiego 27, 50370 Wroclaw, Poland; Tel/Fax: 48717201603;

E-mail: miroslaw.miller@eitplus.pl attractive features of high sensitivity and resolution under high vacuum conditions, has become a useful tool for the qualitative and quantitative detection of gaseous species effusing from the Knudsen cell. Almost all groups of inorganic materials were taken into investigations, such as: borides, carbides, fullerens, nitrates, sulphates, halides, metals, alloys, oxides, glasses, ceramics. Vaporization results and thermodynamic data obtained by the use of the method, were reviewed in several works, e.g. Inghram and Drowart [5], Grimley [6] Drowart [7], Plante and Hastie [8], Drowart et al. [9], Copland and Jacobson [10]. A review of Hilpert [11] covered the thermochemical studies of alloys, oxide and metal halide systems before 1990. The present paper summarizes research activities concerning fullerens in addition to alloys and oxide systems carried out by Knudsen effusion mass spectrometry in the period 1990-2010. 362 original papers were published in the field in this period by ca. 45 research groups. Twenty six KEMS research groups published their results during last five years (2006-2010) thereby showing still large activity in this unique area. Seven of them are working in Russia, presently leading country in use of KEMS technique. Several review papers were published in the latter period dealing with the high temperature mass spectrometric studies of the oxide systems [12-15], fullerens [16] and other systems [17]. Excellent book of Stolyarova and Semenov [18] was published 1994 on the mass spectrometric studies of oxide systems. Several authors developed and used modifications of mass 
spectrometric assembly for thermodynamic studies of alloys [10, 19-21]. Hastie et al. developed an unique method for thermodynamic studies at very high temperatures beyond $3000 \mathrm{~K}[22,23]$.

Most of the investigations of metal alloys and oxide systems were performed in order to determine the thermodynamic properties of condensed phases, such as thermodynamic activities, mixing properties, and Gibbs energies of formation. Other studies were aimed at the identification of gaseous species: clusters, binary oxide species and others. These works are summarized in Sections 3 and 4. In the Section 3 we also reviewed investigations of the metal-nonmetal systems. In the Section 4 glassy and halide-oxide systems are reported as well. Identification and thermodynamic studies of several gaseous species occurring in systems containing fullerens are reviewed in Section 5 separately. An overview of metal halide system investigations will be given by the authors in a separate paper [24].

\section{KNUDSEN EFFUSION MASS SPECTROMETRY}

\subsection{Principles of the Method}

The Knudsen effusion mass spectrometric investigations consist in a mass spectrum analysis of a beam of species effusing through the effusing orifice from the Knudsen cell. An area of the orifice in comparison to the surface of vaporizing substance is so small that the thermodynamic equilibrium in the cell is not disturbed upon effusion of vapours out of the cell. Thus, the content of the qualitative and quantitative effusing molecular beam can be considered as representing the equilibrium vapour in the cell. Once the sample effuses as molecular beam, ions are formed by ionisation and fragmentation processes due to the electron bombardment in ion source. The ions are accelerated in the electric field and then separated in the magnetic field by their mass-to-charge ratio. A Faraday cup or an electron multiplier is used for ion current measurement. Temperature is measured with an optical pyrometer or a thermocouple.

Knudsen cell temperatures and intensities of ion currents originating from ionisation or fragmentation of gaseous species are the quantities measured in the course of an investigation by Knudsen effusion mass spectrometry. Applying equations derived from kinetic theory of gases and chemical thermodynamics to the measured mass spectra, it is possible to:

- identify all gaseous species forming the equilibrium vapor over condensed phases in the Knudsen cell;

- calculate their equilibrium partial pressures in the range from generally between $10^{-5}$ and $10 \mathrm{~Pa}$ and up to temperatures above $2500 \mathrm{~K}$;

- compute thermodynamic properties of gaseous molecules and condensed phases from the determined partial pressures and their temperature dependencies, as, for example, enthalpies and entropies of vaporization, dissociation and formation.

Different Knudsen cell constructions are currently applied depending on the particular target of the investigation $[11,25]$. The cell material used for the study is of big importance due to its possible interaction with the samples. Especially oxides become reactive at high temperatures thereby possibly leading to the interactions. Only few refractory materials, viz. Pt, Mo, W, Ir, and Re (of which Pt and Ir are chemically the most inert) can be used although they have their limitations, as well. At very hightemperature studies of oxide samples, the cell-materials are even more limited to Mo, W and Re. They are, however, not inert and usually interact with oxide systems by formation of gaseous species. On the other hand silica or ceramic materials as $\mathrm{Al}_{2} \mathrm{O}_{3}, \mathrm{ZrO}_{2}$, BN are mostly used as a Knudsen cell material in the investigations of alloys.

Hastie et al. developed a new method for thermodynamic investigations of refractories at very high temperatures beyond $3000 \mathrm{~K}[22,23]$. A pulsed laser beam is used in this method as a heat source. No effusion cell is necessary in this case thereby avoiding the interactions between sample and cell material.

\subsection{Identification of Gaseous Species}

The ions present in the mass spectrum are identified by standard procedures that include the measurement of the mass-to-charge ratio and of the isotopic distribution. A moveable shutter placed between the effusion orifice and the ion source allows distinguishing between ions formed from the effusing vapour and those formed from residual gases in the ion source region of the mass spectrometer.

Thermodynamic interpretation of the mass spectrometric results requires qualitative and quantitative assignment of ions observed in the mass spectrum to their neutral precursors. While qualitative assignment of ions does not encounter many difficulties, quantitative one can do due to the complex vapour composition and fragmentation. Degree and pattern of fragmentation depend on energy of the ionising electrons, molecular structure, chemical bonding and - in some extend - on the temperature of the ionised molecules. One can apply some useful rules for the assignment:

a. the intensities of ions coming from the same molecule show the same or very similar temperature dependencies;

b. the appearance potentials of molecular ions formed by simple ionisation are generally smaller than those of fragments from the same neutral precursor, they increase with increasing degree of fragmentation;

c. the shape of ionisation efficiency curves can indicate fragmentation;

d. fragment ions posses the additional kinetic energy in comparison to molecular ions formed by simple ionisation;

e. homologous gaseous species show similar fragmentation patterns.

Deviations from rules a) and b) are possible due to temperature dependent fragmentation and the formation of negative ions, respectively. The extensive description of aforementioned points is given in [17] and references quoted therein. 


\subsection{Partial Pressures}

Partial pressures of species $i, p(i)$, at temperature $T$ are defined by the equation:

$p(i)=(k T \Sigma I(j, i)) / \sigma(i)$

where $\Sigma I(j, i)$ is sum of intensities of the ion currents $j$ originating from the molecule $i, \sigma(i)$ is the ionisation crosssection of the molecule $i, k$ is the pressure calibration factor which is specific to each measurement and includes geometric factors for the cell and ion source arrangement. When ion $j$ has few isotopes, one of them - usually the most intense - is measured and, on this basis, the amounts of others isotopes are calculated by use of known isotopic distributions.

Three different methods of determination of pressure calibration factor are generally applied [11]. The mostly used technique bases on the mass spectrum measurement of the substance with the well-known partial pressure (usually pure metals: $\mathrm{Ag}, \mathrm{Au}, \mathrm{Ni}, \mathrm{Pt}$ ) at the possibly well defined temperature $T$ (preferentially melting temperature). Applying Eq. (1) the $k / \sigma(i)$ ratio can be obtained in this way. It is required then, while calculating partial pressures of other gaseous species, $n$, identified in vapours to know the ionisation cross-section ratio $\sigma(i) / \sigma(n)$.

Another method of the determination of the pressure calibration factor $k$ bases on the quantitative evaporation of the investigated substance. The mass loss rate $d m(i) / d t$ of a substance $i$, vaporized at the temperature $T$ from the Knudsen cell, is determined by weighing, in addition to the ion intensity measurement. Pressure calibration factor results then from the equation:

$k=\frac{\sigma(i)}{I(i) T} \frac{1}{q C} \sqrt{\frac{2 \pi R T}{M(i)}} \frac{d m(i)}{d t}$,

where $M(i)$ is the molar mass of a component $i$ and $q C$ is the area of the effusion orifice corrected by the Clausing factor C.

The third, rather rarely applied method to the determination of $k$ factor uses a pressure dependent equilibrium, for instance dissociation of dimer species to monomers:

$\mathrm{A}_{2}(\mathrm{~g})=2 \mathrm{~A}(\mathrm{~g})$

which are present in the vapour of the investigated system. Once the equilibrium constant $K_{p}{ }^{\circ}=p(\mathrm{~A})^{2} /\left(p\left(\mathrm{~A}_{2}\right) \cdot p^{\circ}\right)$ is known, the calibration factor can be calculated as follows:

$k=K_{p}^{o} \frac{1}{T} \frac{\sigma(A)^{2}}{\sigma\left(A_{2}\right)} \frac{I\left(A_{2}\right)}{I(A)^{2}}$

Due to the small accuracy of the $K_{p}{ }^{\circ}$ values reported in thermochemical data basis, the latter method is rather uncertain and should be used only for rough estimation.

Relative ionisation cross sections of vapour species are to be known for calculations of partial pressures by use of Eq.(1). The ionisation cross-sections of the atoms, $\sigma(A)$, were computed theoretically by Mann [26, 27]. The values are still used in most works carried out by Knudsen effusion mass spectrometry. In 1980/90th Freund et al. [28-31] measured ionisation cross sections of many atoms concluding a good agreement with previous theoretical values for most chemical elements. To obtain ionisation cross-sections of molecules, $\sigma(M)$, the additivity rule: $\sigma(M)$ $=\Sigma \sigma(A)$, has been suggested by Otvos and Stevenson [32]. More recent studies suggest some modifications of the additivity rule to obtain more reliable ionisation cross sections of the polyatomic molecular species $[33,34]$. It is for instance recommended [7] for obtaining ionization crosssections of monomeric, dimeric and trimeric molecules to apply ratios of cross-sections as follows: 1:1.6:2.6, instead of $1: 2: 3$, as it would result from the additivity rule. There are only few experimental studies on ionisation cross sections of molecules (i.e. [30, 31]). They show, that additivity is often not obeyed for gaseous species. Drowart [7] systematized data on ionization cross-sections of some transition metal oxide molecules obtained experimentally and found that $\sigma\left(\mathrm{M}_{2} \mathrm{O}\right)<\sigma(\mathrm{MO})<\sigma(\mathrm{M})$. Similar contradiction to the additivity rule is known for the series $\sigma\left(\mathrm{SiF}_{4}\right)<\sigma\left(\mathrm{SiF}_{3}\right)<$ $\sigma\left(\mathrm{SiF}_{2}\right)<\sigma(\mathrm{SiF})$ [35-37]. The latter case was explained by the theoretical analysis of chemical bonding in the gaseous species [38]. It seems that theoretical, particularly quantumchemical calculations will give more reliable data on ionisation cross sections of molecules in comparison to the empirical rules used nowadays [39-43].

\subsection{Thermodynamic Properties}

Knowledge of partial pressures of the gas phase components in the system at the temperature $T$, allows determining the equilibrium constants, $K_{\mathrm{p}}^{\circ}$, of the investigated reactions according to the equation:

$K_{p}^{o}=\Pi\left(\frac{p(i)}{p^{o}}\right)^{v_{i}}$,

where $v_{i}$ is the stoichiometric coefficient of the reaction, and $p^{\circ}$ denotes the standard pressure (typically $1 \mathrm{bar}=10^{5} \mathrm{~Pa}$ ).

The values of equilibrium constants yield Gibbs energies for reactions studied:

$\Delta_{\mathrm{r}} G^{\circ}(T)=\Delta_{\mathrm{r}} H^{\circ}(T)-T \Delta_{\mathrm{r}} S^{\circ}(T)=-R T \ln K_{\mathrm{p}}^{\circ}(T)$,

where $R$-gas constant, $8.314 \mathrm{~J} \mathrm{~mol}^{-1} \mathrm{~K}^{-1}$.

Enthalpy changes, $\Delta_{\mathrm{r}} H^{\circ}$, can be determined from the experimental values of $K_{\mathrm{p}}^{\circ}$ in two independent ways according to the so-called second and third-law methods. Second law enthalpy of the reaction bases on the equilibrium constant measurement in a certain temperature range and is evaluated using the van't Hoff's isobar:

$\frac{d \ln K_{p}{ }^{\circ}(T)}{d(1 / T)}=\frac{-\Delta_{\mathrm{r}} H^{\circ}\left(T_{\mathrm{m}}\right)}{R}$,

where $T_{\mathrm{m}}$ is the mean temperature of the measurement. Regression coefficient $A$ and intercept $B$ are usually obtained by the least-squares method from the following temperature dependence of $K_{\mathrm{p}}{ }^{\circ}$ :

$\ln K_{\mathrm{p}}^{\circ}(T)=A / T+B$.

The values of $A$ and $B$ coefficients allow enthalpy and entropy changes at mean temperature of the measurement to be calculated by use of the relationships: 
$A=\frac{-\Delta_{\mathrm{r}} H^{\circ}\left(T_{\mathrm{m}}\right)}{R}$

$B=\frac{\Delta_{r} S^{\circ}\left(T_{m}\right)}{R}$

The values of enthalpy and entropy of the reaction at the mean temperature of the measurement can be converted into the standard temperature, $T_{\text {st }}$, (usually $298 \mathrm{~K}$ or $0 \mathrm{~K}$ ) by use of the $C_{\mathrm{p}}{ }^{\circ}(T)$ functions or enthalpy increments $H(T)-H\left(T_{\mathrm{st}}\right)$ for all reactants taking part in the reaction. The functions of many compounds are tabulated in thermodynamic compilations (e.g. [44-46]).

Enthalpy changes can be as well evaluated according to the third law method by the use of the following equation:

$\Delta_{r} H^{\circ}(298)=-T\left[\operatorname{RIn} K_{P}^{\circ}+\Delta_{r} G E F^{\circ}(T)\right]$,

where $\Delta_{\mathrm{r}} G E F^{\circ}(T)$ is the change of the Gibbs energy function for the reaction considered. The $\Delta_{\mathrm{r}} G E F^{\circ}(T)$ values can be obtained from the Gibbs energy functions of the reacting materials. The $G E F^{\circ}(T)$ functions are as well tabulated for many compounds in different phases and at different temperatures. In case of gaseous species, Gibbs energy function can be computed from known or estimated molecular parameters by the use of statistical thermodynamics. Quantum chemical calculations are frequently used for estimations of structure of gaseous species (e.g. [47]). Rules for the estimation of Gibbs energy functions for condensed phases are given for instance by Kubaschewski and Alcock [48].

The evaluation of the thermodynamic properties of condensed phases by Knudsen effusion mass spectrometry was previously reviewed [11]. The thermodynamic activities can be obtained from the partial pressures of the mixture components. To omit uncertainties caused by the calibration procedure and estimations of ionisation cross sections mentioned above, methods were developed, which yield thermodynamic data directly from the measured ion intensities of components. Description of these methods is discussed in details elsewhere [49, 50]. Method of the integration of the ion intensity ratio bases on the GibbsDuhem equation and was developed independently by Lyubimov [51], Belton and Fruehan [52] and Neckel and Wagner [53]. Another method requires the special multi-cell assembly allowing the ion current of mixture component and of standard sample (for instance a pure component) to be detected in the same experiment [19-21, 25]. Use of the standard Knudsen effusion assembly is also possible for detecting ion intensity of mixture component and of standard substance providing the constant sensitivity of the mass spectrometer. It can be achieved with the accuracy of $5-10 \%$ if ion source is not switched off in a experimental series and the same effusion orifice is used (i.e. [54]).

In some specific cases a so called monomer/dimer method is usable for the determination of thermodynamic activities [55]. The method enables the measurement of the activity of components vaporising in the form of two different oligomers (usually: monomers and dimers). Direct comparison of the ratio of ion intensities originated from both oligomers detected for pure component and upon vaporising a multicomponent sample gives the value of its thermodynamic activity without necessity of calibration procedure. The method does not require a stability of sensitivity of mass spectrometer during a series of measurements.

Knowledge of thermodynamic activities results also in partial and integral mixing functions and in the thermodynamic functions of formation of condensed phases. Data necessary for construction of phase diagrams (as homogeneity ranges, solubilities) can also be obtained from vaporisation experiments carried out by Knudsen effusion mass spectrometry [22, 56-58].

A comment should be done to the comparison of the reviewed method with other techniques used for the thermodynamic investigations of chemical substances. Calorimetric methods are the most accurate for the enthalpy determinations. Electrochemical methods, in turn, yield the Gibbs energies and thermodynamic activities of mixed components. Data obtained by Knudsen effusion mass spectrometry yield thermodynamic activities of components. Both KEMS and EMF result in Gibbs energies of chemicals, while their enthalpies and entropies can be obtained indirect from the temperature dependencies of Gibbs energies. Usually EMF is applicable at temperatures very different (lower) in comparison to these applied in mass spectrometric studies. Therefore, it is the most advantageous to combine Gibbs energies resulted from KEMS and/or EMF, with enthalpies determined by the calorimetric methods.

In Sections 3-5 we report briefly on experimental data obtained by KEMS for metal alloys, oxides and fullerens in the period 1990-2010. Basic information on pure metals (Table 1), alloys (Table 2), metal-nonmetal (Table 3), oxide (Table 4), glass (Table 5), halide-oxide (Table 6), and fullerene (Table 7) systems investigated is summarised and the original works are cited in Supplementary material. Therefore in Sections 3-5 only example paper are quoted to be more briefly. Sample compositions, temperature range, gas species identified as well as thermodynamic quantities reported in the particular paper are given in Tables if available from the original paper given in Supplementary material. The respective paper concerning the specific issue reported in Sections 3-5 can be easily identified in Tables 1-7.

\section{METALS AND ALLOYS (NUMBER OF PUBLISHED PAPERS: 191)}

\subsection{Identification of Gaseous Clusters and Their Thermodynamic Properties}

Some papers published in the reviewed period on the metal alloy systems were carried out in order to study vapour clusters. These works are reported in Supplementary material, Table 1 together with studies of vaporisation of pure metals. Different homoclusters identified over pure elements of which silicon, germanium, and tin were the most extensive studied by Gingerich et al. Clusters build from up to $8 \mathrm{Si}$ or $\mathrm{Ge}$ and $7 \mathrm{Sn}$ atoms were identified in the equilibrium vapours of the elements. As expected from the complex composition of the pure $\mathrm{Ge}, \mathrm{Sb}, \mathrm{Sn}$, and Te vapours, mixtures containing these elements in addition to other metals are complex as well. Heteroclusters as $\mathrm{Cs}_{6} \mathrm{Sb}_{4}$, and $\mathrm{Ge}_{4} \mathrm{Sn}$ are, for instance, reported in the published 
studies. Molecules containing polyanions, molecules with Zintl anions, and molecules with Zintl cations were observed over alkali tellurides. For studies carried out at very high temperatures, interactions of samples with the crucible material was evident by observing the gaseous products $\mathrm{SnC}$ or $\mathrm{OsC}, \mathrm{OsC}_{2}$. In several studies experimental data obtained by the mass spectrometry were supported by the advanced quantum-chemical calculations to the gaseous clusters identified in vapours. The aim of these calculations was to study of the chemical structure and bonding in the clusters and estimation of their thermochemical functions, needed for the third law computing of data. The second law calculations of vaporisation enthalpy of the complex clusters were rather rarely performed due to a narrow temperature range of their evidence as minor species. Gibbs energies and enthalpies of formation were determined in cited papers for gaseous species underlined in Supplementary material, Table $\mathbf{1 .}$

\subsection{Thermodynamic Properties of Condensed Phases}

Most of the investigations on the alloy systems carried out by Knudsen effusion mass spectrometry resulted in thermodynamic properties of condensed phases. They are summarized in Supplementary material, Table 2. If liquid alloys or solid solutions were studied, usually all composition range was covered by the investigated samples. If the solid intermetallic compounds occurred in the system studied, proper compositions were chosen in order to determine the formation thermodynamics of these compounds. Intermetallics which certain studies were focused on are underlined in Table 2.

In the reviewed period much interest was focused on the alloys, which are of large importance for high temperature technologies. Two groups: Hilpert et al. and Jacobson et al. carried out an extensive investigation of superalloys based on the $\alpha$-phase (NiAl, TiAl) and $\gamma$-phase $\left(\mathrm{Ni}_{3} \mathrm{Al}, \mathrm{Ni}_{3} \mathrm{Ti}\right)$. Aim of the studies was to determine the component activities in samples and to predict the resistance of the alloys against oxidation at high temperature. Chemical composition of oxide layer forming at the alloy surface upon oxidation depends on the thermodynamic activities of the alloy components. Studies were also carried out on the influence of other metals as $\mathrm{Cr}$, $\mathrm{Fe}, \mathrm{Co}, \mathrm{Hf}, \mathrm{Nb}$ on the thermodynamic activities of the main components in the Ni-Al and Ti-Al alloys.

Vrestal, Tomiska et al. studied different alloys composed of $\mathrm{Cr}, \mathrm{Fe}, \mathrm{Co}, \mathrm{Ni}, \mathrm{Pd}$ and other metals in all composition range and for both liquid and solid phase. These alloys form mostly solid solutions without any intermetallic phases. Determination of thermodynamic functions obtained were used by the authors for the computer modelling of phase diagrams of the systems leading to very accurate determinations of the liquidus, solidus and other phase boundaries (computer-aided Knudsen cell mass spectrometry). Balducci et al. studied vaporization of binary systems $\mathrm{Ru}-\mathrm{Ge}$, Ru-Sn, $\mathrm{Pd}-M, M=\mathrm{In}, \mathrm{Sn}, \mathrm{Pb}$, which are of interest due to their thermoelectric, semiconducting and catalytic properties. Thermodynamic properties of intermetallic phases was the aim in most of these studies. Importance for electronics, optical recording (In-Te, Ag-In$\mathrm{Sn}, \mathrm{Cr}-\mathrm{Ge}, \mathrm{Cu}-\mathrm{Nd}$ ), as well as for development of the $\mathrm{Pb}-$ free soldering materials (Ag-In-Sn) exemplifies motivations of other studies of alloys for practical use.
Different Te-alloys were studied by the group of Viswanathan et al. Motivation of these studies was a possible generation of volatile Te during nuclear fission and chemical interaction in the fuel-clad. Dimer $\mathrm{Te}_{2}(\mathrm{~g})$ is the most volatile component in these systems. Quantitative depletion of Te from samples yielded information to the thermodynamic activity change upon crossing different phase fields due to the change of the chemical composition of samples. Studies of lanthanide and actinide containing alloys were also carried out due to their importance for nuclear technologies. A series of solid and liquid binary alloys of lanthanides and uranium was studied by a group of Matsui et al. Thermodynamic activities of one or both components were possible to be determined depending on their volatility. Some other alloys containing uranium and plutonium were studied by Maeda et al., Yamaki et al. and Gardie. Finally, studies of thermodynamic properties of the multicomponent alloys being already in use should be mentioned. For instance volatilisation and thermodynamic activities of the most volatile components of ODS alloy MA 6000 and Zircaloy-4 with admixture of Te were studied.

Table $\mathbf{3}$ in Supplementary material reports studies of systems containing non-metallic element ( $\mathrm{B}, \mathrm{Si}, \mathrm{P}, \mathrm{As})$ in addition to metallic components. For liquid systems, thermodynamic activities of components were obtained in these studies. As far, as systems in solid state were studied, thermodynamic properties of binary compounds (borides, silicides, phosphides, etc.) were obtained from the thermodynamic activities. Extensive investigations of different binary and ternary systems containing non-metal element $(\mathrm{B}, \mathrm{Si}$, or $\mathrm{P})$ in addition to $\mathrm{Mn}, \mathrm{Cr}$, and $\mathrm{Fe}$ were carried out by Zaitsev et al.

Strategy of the investigations of the solid alloys depends on the phase relationships in the system under study and on volatility of the alloy components. If the components form a continuous solid solution, a series of alloys is usually prepared (for instance each $10 \mathrm{~mol} \%$ ) and ion intensities of most volatile components are detected in some temperature range. Thermodynamic activities are than calculated at the mean temperature of investigations. Temperature dependences of ion intensities, if recorded, yield partial excess enthalpies of the respective components. Thermodynamic functions are presented as a function of the alloy composition by use of one of the mathematical models (mostly Redlich-Kister equation). If the activity of only one component (in binary systems) or two components (in ternary systems) can be determined, the missing one is usually evaluated by integration of the GibbsDuhem equation.

Alloys forming solid intermetallic compounds are typically studied by supplementary methods (e.g. [59]). Samples compositions are chosen depending on phase diagram and usually are composed of two (binaries) or three (ternaries) phases which are checked by the XRD phase analysis. In such phase fields the partial pressures are independent on chemical composition of samples and change only while crossing phase boundaries. For this reason, in order to carry out the complete study a binary system forming binary compounds, minimal number of samples required is same as number of compounds. Many intermetallic phases are, however, not strictly stoichiometric compounds but show the homogeneity ranges even of 20 
mol $\%$ as in case of TiAl phase occurring in the Ti-Al system [60]. In this case, monophase samples are to be investigated in addition to the two-phase samples in order to get full thermodynamic description of the system. Usually significantly more samples are needed to be studied in ternary system to cover its all composition range. This is a reason why only particular sections of the ternary systems are investigated in most cases.

Strictly stoichiometric compounds are not suitable for study by use of Knudsen effusion mass spectrometry. Due to depletion of the more volatile component from the Knudsen cell, chemical composition of such samples shifts giving rise to change of the partial pressures - and thereby also measured ion intensities - on time. The pressures become time-independent only after sample becomes multiphase one. Then it contains one of the phases adjacent to the stoichiometric compound in addition to this compound.

\section{OXIDES (NUMBER OF PUBLISHED PAPERS: 221)}

Oxides are widely used and encountered in technical applications, such as high-temperature electrolytes, sensors, superconductors, glasses, functional layers and others. Knudsen effusion mass spectrometry is often applied for the investigations of the thermodynamic properties of these materials. In order to optimise the chemical composition of the oxide material used in the technological processes, thermodynamic stability and vaporization has to be known. The most extensive compilations on vaporization of oxides was given in 1994 by Stolyarova and Semenov [18]. Table 4 in Supplementary material shows the studies on oxide systems carried out by Knudsen effusion mass spectrometry over the reviewed period.

There are several specific problems concerning the studies of oxide systems by this method. Probably the most important are interactions between the effusion cell material and vapours of the oxide system. These interactions result in the oxygen potential which is specific for the thermodynamic equilibrium between gaseous phase and the cell/sample interface. This interaction should not influence on the thermodynamic data obtained from the experimental mass spectra providing the studied oxide phase is thermodynamically stable upon the experimental conditions and the equilibrium oxygen potential can be determined. Advantageous are studies of oxide systems with use of different Knudsen cell materials and thereby different equilibrium oxygen partial pressures. Agreement of thermodynamic functions obtained in such studies confirms reliability of the data.

Another specific problem for the vaporization investigations of oxide systems is a small vaporization coefficient, particularly for the refractory oxides. Possibly large ratio between vaporisation (sample) surface and effusion orifice area should be, therefore, kept in the vaporisation study. Different effusion orifice dimensions are used in some studies in order to check whether pressures obtained are the same as expected under the equilibrium conditions [61].

Following phenomena can be, additionally, observed on studying the oxide and ceramic materials by Knudsen effusion mass spectrometry at high temperatures: a. interaction of the vapours with the gas medium surrounding the cell;

b. oxygen diffusion through the cell material (the use of effusion cells made out of monocrystalline tungsten is suggested in Ref. [17] to avoid this phenomenon);

c. chemical reduction of the sample by the cell material;

d. formation of new solid phases at the contact boundary of the cell with the sample.

Studies carried out by Hilpert et al. have shown, that use of the effusion cells machined from Ir enable to avoid the most of the quoted effects even upon studying refractory ceramics at temperatures up to $2200 \mathrm{~K}$.

Among the oxide systems studied in the reviewed period, only few are pure compounds. For instance, vaporization of tin and lead oxides were carried out in spite of several studies of these compounds in the past. These studies confirmed the previous results showing that both compounds vaporize in the form of oligomers up to hexamer. Complex oxide species were also identified upon vaporizing $\mathrm{TeO}_{2}$ $\left((\mathrm{TeO})_{x},\left(\mathrm{TeO}_{2}\right)_{x}, x=1-3\right)$. Other studies on pure oxides concerned $\mathrm{ZnO}, \mathrm{PuO}_{2}, \mathrm{Ti}_{10} \mathrm{O}_{19}$ and some other compounds (Table 4). $\mathrm{PdO}(\mathrm{g})$ species was identified and investigated in the $\mathrm{Pd}(\mathrm{s}) / \mathrm{O}_{2}$ system. Vaporisation of $\mathrm{SiO}_{2}, \mathrm{~V}_{2} \mathrm{O}_{5}$, and $\mathrm{Tc}_{\mathrm{x}} \mathrm{O}_{\mathrm{y}}$ in the $\mathrm{H}_{2} \mathrm{O}$ atmosphere was also investigated. Gaseous hydroxides and oxyhydroxides were identified in these studies in addition to the vapour species present over respective pure oxides.

Most studies of oxide systems were carried out for elucidating of the vaporization of binary oxide phases and compounds. This is due to the increasing importance of such chemicals in the modern technologies (SOFC and other chemical batteries, sensors, improving layers, superconductors a.s.o.). Titanates, chromates, vanadates, and gallates of the perovskite structure were intensively investigated by different groups. Other pseudobinary oxide phases as phosphates, zirconates, molybdates, bismuthates, niobates, tellurates, tantalates, tungstates, or uranates, were extensively studied by different groups in order to obtain the high temperature thermodynamic characteristics of these compounds. Most of these compounds vaporize incongruently by depleting of the more volatile components. In many cases complex vapour species were identified in the equilibrium vapours in addition to gaseous species characteristic for the vaporization of pure oxide components. In the cited studies thermodynamic functions of formation were determined for the vapour complex species in addition to the thermodynamic activities of components in condensed phase. Thermodynamic properties of gaseous $\mathrm{LiVO}_{3}$, $\mathrm{Li}_{2} \mathrm{MoO}_{4}, \mathrm{NaBiO}_{2}, \mathrm{CsBiO}_{2}, \mathrm{KVO}_{3}$, and $\mathrm{BaWO}_{4}$, were for instance studied in the cited papers. Lopatin et al. carried out the extensive studies of binary phosphates of the I, II and III group elements and published a review on the vaporization of these compounds [62]. He formulated conclusions concerning the vapour phase composition of phosphates as a function of the metal cation properties. High temperature properties of plutonium and uranium oxides and different systems containing these oxides were studied due to the importance for nuclear technology. 
Over 30 binary and multicomponent borate or silicate glasses were studied in the reviewed period by the Knudsen effusion mass spectrometry. They are summarized in Supplementary material, Table 5. Vapour phase of the boron oxide-containing systems is rather complex due to the vaporization of $\mathrm{B}_{2} \mathrm{O}_{3}$ in form of different gaseous species $\left(\mathrm{BO}, \mathrm{B}_{2} \mathrm{O}_{2}, \mathrm{~B}_{2} \mathrm{O}_{3}\right)$ as well as due to stability of the gaseous metal borides, as $A \mathrm{BO}_{2}\left(A\right.$ - alkali metal), $\mathrm{Ca}\left(\mathrm{BO}_{2}\right)_{2}, \mathrm{SrBO}_{2}$, $\mathrm{BaBO}_{2}$. Dimeric borate species $A_{2}\left(\mathrm{BO}_{2}\right)_{2}$ were identified as well. Silica-containing materials vaporize typically as $\mathrm{SiO}(\mathrm{g}), \mathrm{O}_{2} / \mathrm{O}(\mathrm{g})$ and the component metal oxides if their volatility is high enough. High stability of the gaseous silicium monoxide is very well established. Few gaseous silicates were identified in the multicomponent silicate systems; they can be exemplified by $\mathrm{CaSiO}_{3}, \mathrm{BaSiO}_{3}, \mathrm{SrSiO}$, and $\mathrm{AlSiO}$ all being the minor components of the equilibrium vapours. The same deals with the aluminate systems, where only minor amounts of $\mathrm{CaAlO}(\mathrm{g})$ could be identified in the cited studies. $\mathrm{Al}_{2} \mathrm{O}(\mathrm{g})$ is a major $\mathrm{Al}$ containing species in all the system containing $\mathrm{Al}_{2} \mathrm{O}_{3}$ as one of the oxide components. Chatillon et al. studied ternary systems containing silica in addition to the metal phosphates. Determination of the thermodynamic activities of components was the aim of these studies.

Studies carried out on vaporization of the mixed oxide/halide systems are also reported in Supplementary material, Table 6. Such systems are of practical importance for instance as slag models (e.g. [63]). Interesting interactions of components were found out in some studies leading to the formation of "exotic" vapour species. Among them $\mathrm{Ca}_{3} \mathrm{O} X_{4}(\mathrm{~g}), \mathrm{Ca}_{4} \mathrm{O} X_{6}(\mathrm{~g}), X=\mathrm{Br}$, I, and $\mathrm{Dy}_{2} \mathrm{OF}_{4}(\mathrm{~g})$ should be mentioned. Other gaseous oxyhalides: AlOF , $\mathrm{AlOCl}$, and DyOF were identified in the studies cited in Table $\mathbf{6}$ as well.

\section{FULLERENS AND DERIVATIVES (NUMBER OF PUBLISHED PAPERS: 30)}

Fullerens were discovered and developed only in late $1980^{\text {th }}$ and for this reason this group of compounds was not reviewed in the former article [11]. Since the beginning of the discovery of fullerens, Knudsen effusion mass spectrometry was widely applied for the investigations of this new carbon form. Table 7 summarizes these investigations together with their most important results. Partial pressures and sublimation enthalpies of pure $\mathrm{C}_{n}$ for different $n$ were determined in groups of Sidorov et al. as well as of Mathews et al. by use of conventional Knudsen effusion mass spectrometry described in Section 2. Much effort was concentrated on studies of ionisation and fragmentation processes as well as on determination of electron affinities. These studies resulted in better understanding of structure and bonding in different fullerens. Studies of the fullerene mixtures yielded the thermodynamic activities and partial molar quantities. Vapour phase interactions between fullerens and other gaseous species were extensively studied leading to the development of the fullerene hydrides (e.g. $\mathrm{C}_{60} \mathrm{H}_{18}$ ) halides (e.g. $\mathrm{C}_{60} \mathrm{~F}_{2}, \mathrm{C}_{60} \mathrm{~F}_{48}$, $\mathrm{C}_{70} \mathrm{Cl}_{14}$ ) and of a new class of compounds metal-fullerene (e.g. $\mathrm{K} @ \mathrm{C}_{70}, \mathrm{Gd} @ \mathrm{C}_{60}$ ). Partial pressures, sublimation enthalpies and electron affinities of these species were investigated as shown in Table 7.

\section{SUMMARY AND CONCLUSIONS}

Investigations carried out by Knudsen effusion mass spectrometry on the metal, oxide, and fullerene systems in the period 1990-2010 are reviewed in the present paper. The emphasis of this article is placed on subject belonging to the research interest of both authors. The fundamentals and recent developments of the method are briefly reported. Data to the systems studied, temperature ranges, vapour species identified in the equilibrium vapours and thermodynamic properties obtained in the study are given in Supplementary material, Tables 1-7.

Numerous new, original results have been obtained during the reviewed period. Some of them are given in the following examples:

- investigations of metal clusters: large homo- and heteroclusters such as $\mathrm{Ge}_{8}(\mathrm{~g})$ and $\mathrm{Ge}_{4} \mathrm{Sn}(\mathrm{g})$ were identified and their thermodynamic properties determined; sophisticated quantum-chemical calculations were carried out in order to elucidate their chemical bonding and to get their structure parameters;

- investigations of alloys: extensive studies of the materials of practical relevance (e.g. Ni-Al, Ni-Ti, and $\mathrm{Ni}-\mathrm{Ti}-\mathrm{Al}$ ) were carried out; thermodynamic stability of phases and formation functions of solutions or intermetallics were determined;

- investigations of oxide systems: thermodynamic stability and volatility of perovskites and other pseudobinary phases were investigated (titanates, chromates, vanadates, gallates, zirconates, niobates, tantalates, molybdates, bismuthates, tellurates, tungstates, uranates); a systematic study of vaporization of metal phosphates was carried out as well; a lot of the oxide systems relevant for technologies were described;

- investigations of glass systems: several studies were carried out on multicomponent systems based on $\mathrm{B}_{2} \mathrm{O}_{3}, \mathrm{SiO}_{2}$, and $\mathrm{Al}_{2} \mathrm{O}_{3}$; thermodynamic activities were determined and - in some cases - complex oxide species were identified and characterized;

- investigations of fullerenes: basic thermodynamic properties and ionisation processes of pure fullerenes were studied; gaseous reaction products between fullerenes and halogens or metals were identified and characterized.

Most of the vaporization studies by Knudsen effusion mass spectrometry carried out on alloys and oxides aimed at the determination of thermodynamic data of condensed phases. Many of the studied materials are of practical importance for the modern technologies. The investigations should give information on thermal stability, volatility under different conditions (temperature, oxygen partial pressure, gaseous impurities), oxidation resistance, reactivity etc.

Moreover, the review shows that numerous gaseous species have been identified for the first time and thermodynamic properties evaluated for investigated metals as well as alloys or oxide systems. In this field, clusters of heavy elements $(\mathrm{Sn}, \mathrm{Os}, \mathrm{Bi})$ are the most interesting. First 
evidence of $\mathrm{Pd}$ clusters $(\mathrm{PdPb}, \mathrm{PdSn})$ should be also mentioned in this context.

A disadvantage of Knudsen effusion mass spectrometry is its limitation to comparatively low pressures up to about $10 \mathrm{~Pa}$. Another disadvantage is possible interaction of vapours with a cell material, what is particularly important for oxide systems. Equilibrium oxygen partial pressure in these systems often results not only from the dissociative vaporisation of sample but also from the stability of the oxides of the respective effusion cell material. For the reason a big care should be taken while interpreting data obtained for oxide systems by Knudsen effusion mass spectrometry.

During 60 years that have passed since the pioneering studies by Ionov [2] and Chupka and Inghram [3], our knowledge of the chemistry of inorganic vapours has increased substantially. Nowadays the method is still a powerful tool for thermodynamic investigations of inorganic materials via the determination of the composition of the equilibrium gaseous phase. Some other studies of systems previously described were reinvestigated in order to improve data by using of better instrumentation or evaluation methods (e.g. quantum-chemical calculations). Minor gaseous species are possible to be identified in the vapours due to the enhanced sensitivity of modern electronic devices. These species are often of great interest for the fundamental research on molecular structure and chemical bonding.

In spite of very specific applications of Knudsen effusion mass spectrometry, the method is becoming one of the three most useful tools for determination of high temperature thermochemical data of inorganic materials, calorimetric and electrochemical methods being the other ones. Advantages of Knudsen effusion mass spectrometry are: higher temperatures than can be obtained in the other methods and the possibility of quantitative analysis of the vapour composition what is specific for the method reviewed.

\section{CONFLICT OF INTEREST}

The authors confirm that this article content has no conflicts of interest.

\section{ACKNOWLEDGEMENT}

Declared none.

\section{SUPPLEMENTARY MATERIAL}

Supplementary material is available on the publisher's web site along with the published article

\section{REFERENCES}

[1] M. Knudsen, "Die Gesetze der Molekularströmung und der inneren Reibungsströmung der Gase durch Röhren," Annalen der Physik, vol. 29, pp.75-130, 1909.

[2] N.I. Ionov, "Ionisation of $\mathrm{KI}, \mathrm{NaI}$ and $\mathrm{CsCl}$ molecules by electrons," Dokl Akad Nauk SSSR, vol. 59, pp. 467-469, 1948.

[3] W.A. Chupka and M.G. Inghram, "Direct determination of the heat of sublimation of Carbon with the Mass Spectrometer," Journal of Physical Chemistry, vol. 59, pp. 100-104, 1955.

[4] R.E. Honig, "Mass Spectrometric Study of the Molecular Sublimation of Graphite," Journal of Chemical Physics, vol. 22, pp. 126-131, 1954.

[5] M.G. Inghram and J.Drowart, "Mass Spectrometry Applied to High Temperature Chemistry," Proceedings of International Symposium on High Temperature Technology, Asilomar, California, McGrawHill, New York, 1960.

[6] R.T. Grimley. In: The Characterization of High-Temperature Vapours, J.L. Margrave, John Wiley, New York, 1967, pp. 195243.

[7] J. Drowart, “Advances in Mass Spectrometry,” 1985, Ed., J. Todd, Ed. John Wiley and Sons, Chichester, New York, 1986, vol. 10a, pp. 195-214.

[8] E.R. Plante and J.W. Hastie, "High temperature Mass Spectrometric studies of inorganic systems," High Temperature Science, vol. 10, pp. 357-378, 1989.

[9] J. Drowart, C. Chatillon, J. Hastie, D. Bonnell, "High-temperature Mass Spectrometry: instrumental techniques, ionization crosssections, pressure measurements, and thermodynamic data" Journal of Pure Applied Chemistry, vol. 77, pp. 683-737, IUPAC Report, 2005.

[10] E.H. Copland, N.S. Jacobson, "Measuring thermodynamic properties of metals and alloys with Knudsen Effusion mass spectrometry," 2010, NASA Report, NASA/TP_2010-216795. Available: http://gltrs.grc.nasa.gov

[11] K. Hilpert, "Chemistry of inorganic vapors," In: Chemistry of Inorganic Vapors, Springer Verlag, Berlin Heidelberg, 1990, vol. 73, pp. 97-198.

[12] C. Bergman, F. Bennour, R. Chastel, J. Rogez, J.C. Mathieu, "Thermodynamic study of Oxide systems by Knudsen-Effusion coupled with Mass Spectrometry," Reviews in Metallic-Cahiers Information Techniques, vol. 95, pp. 1101-1108, 1998.

[13] V.L. Stolyarova, "High temperature Mass Spectrometric study of Oxide systems and materials," Rapid Communications in Mass Spectrometry, vol. 7, pp. 1022-1032, 1993.

[14] V.L. Stolyarova, "High temperature Mass Spectrometric studies of thermodynamic properties of Glass-Forming systems", High Temperature Science, vol. 26, pp. 405-414, 1990.

[15] V.L. Stolyarova, "Vaporization features of Oxide systems studied by high-temperature Mass Spectrometry," Journal of Nuclear Materials., vol. 247, pp.7-10, 1997.

[16] O.V. Boltalina, D.B. Ponomarev, L.N. Sidorov, "Thermochemistry of Fullerene Anions in the Gas Phase," Mass Spectrometry Reviews, vol. 16, pp. 333-351, 1997.

[17] L.N. Sidorov, "High temperature studies," International Journal of Mass Spectrometry and Ion Processes, vol. 118/119, pp. 739-754, 1992.

[18] V.L. Stolyarova and G.A. Semenov, Mass Spectrometric Study of the Vaporization of Oxide Systems, John Wiley \& Sons Ltd., Chichester, England, 1994.

[19] M.J. Stickney, M.S. Chandrasekharaiah, K.A. Gingerich, "TwinChamber Knudsen Effusion Cell Mass-Spectrometer for Alloy Thermodynamic Studies," High Temperature Science, vol. 26, pp.187-195, 1990.

[20] N.S. Jacobson, "Twin Knudsen cell configuration for activity measurements by Mass Spectrometry," High Temperature Science, 1996, vol. 35, pp. 1-9,1996.

[21] C. Chatillon, L.-F. Malheiros, P. Rocabois, M. Jeymond, "Hightemperature Mass Spectrometry with the Knudsen cell: II. technical constraints in the Multiple-cell method for activity determinations," High Temperature -High Pressure, vol. 34, pp. 213-233, 2002.

[22] J. W. Hastie, D.W. Bonnell, P.K. Schenck, "Development and application of very high temperature Mass spectrometry: vapor pressure determinations over liquid refractories," Pure Applied Chemistry, vol. 72, pp. 2111-2126, 2000.

[23] J. W. Hastie, D.W. Bonnell, P.K. Schenck, "Application of new thermochemical measurement method for nuclear materials at temperature beyond 3000K" Journal of Nuclear Materials, vol. 294, pp. 175-178, 2001.

[24] K. Armatys, and M. Miller, "Thermodynamic Studies of Metal Halides by Means of Knudsen Effusion Mass Spectrometry"; A Review, to be published in J. Thermodynamics, 2013.

[25] E. H. Copland, N.S. Jacobson, "Thermodynamic Activity Measurements with Knudsen Cell Mass Spectrometry," The Electrochemical Society Interface, vol. 10 no. 2, pp. 28-31, 2001.

[26] J.B. Mann, Recent Development in Mass Spectrometry, K. Ogata and T. Hayakwa, University Park Press, Baltimore, Tokyo and New York, Eds. 1970, pp. 814-819.

[27] J.B. Mann, "Ionization Cross Sections of the Elements Calculated from Mean-Square Radii of Atomic Orbitals," Journal of Chemical Physics, vol. 46, pp. 1646-1651, 1967. 
[28] R.S. Freund, R.C. Wetzel, R.J. Shul, and T.R. Heyes, "Crosssection measurements for electron-impact ionization of atoms" Physical Review A, vol. 41, pp. 3575-3595, 1990.

[29] T.R. Heyes, R.C. Wetzel and R.S. Freund, "Absolute electronimpact-ionization cross-section measurements of the Halogen atoms," Physical Review A, vol. 35, pp. 578-584, 1987.

[30] R.J. Shul, R.S. Freund, R.C. Wetzel, "Electron-impact-ionization cross sections of $\mathrm{GaCl}, \mathrm{GeCl}$, and $\mathrm{SnCl}$," Physical Review A, vol. 41, pp. 5856-5860, 1990.

[31] R.S. Freund, R.C. Wetzel, R.J. Shul, "Measurements of electronimpact-ionization cross sections of $\mathrm{N} 2, \mathrm{CO}, \mathrm{CO}_{2}, \mathrm{CS}, \mathrm{S}_{2}, \mathrm{CS}_{2}$ and metastable" Physical Review A, vol. 41, pp. 5861-5868, 1990.

[32] J.W. Otvos and D. P. Stevenson, "Cross-sections of molecules for ionization by electrons" Journal of the American Ceramic Society, vol. 78, pp. 546-551, 1956.

[33] H. Deutsch, K. Becker, T.D. Märk, "A modified additivity rule for the calculation of electron-impact ionization cross sections of molecules of the form ABn," International Journal of Mass Spectrometry and Ion Processes, vol. 167/168, pp. 503-517, 1997.

[34] J. W. Hastie, D.W. Bonnell, P.K. Schenck, "Development and application of very high temperature Mass Spectrometry: vapor pressure determinations over liquid refractories". In: 10th International IUPAC Conference of High Temperature Material Chemistry, 10-14 April, 2000, Jülich: Germany.

[35] T. R. Hayes, R. C. Wetzel, F. A. Baiocchi, R. S. Freund, "Absolute Cross Sections for Electron-Impact Ionization and Dissociative Ionization of the SiF Free Radical," Journal of Chemical Physics, vol. 88, pp. 823-829, 1988.

[36] R. J. Shul, T. R. Hayes, R. C. Wetzel, F. A. Baiocchi, R. S. Freund, "Electron impact ionization cross sections of $\mathrm{SiF}_{2}$," Journal of Chemical Physics, vol. 89, pp. 4042-4047, 1988.

[37] T. R. Hayes, R. J. Shul, F. A. Baiocchi, R. C. Wetzel and R. S. Freund, "Electron-impact ionization cross sections of the $\mathrm{SiF}_{3}$ free radical," Journal of Chemical Physics, vol. 89, pp. 4035-4041, 1988.

[38] H. Deutsch, C. Cornelissen, L. Cespiva, V. Bonacic-Koutecky, D. Margreiter, T.D.Märk, "Total electron impact ionization cross sections of free molecular radicals: the failure of the additively rule revised," International Journal of Mass Spectrometry and Ion Processes, vol. 129, pp. 43-48, 1993.

[39] H. Deutsch, K. Becker, S. Matt, and T.D. Märk, "Calculations of cross sections for the electron impact ionization of molecules" International Journal of Mass Spectrometry, vol. 197, pp. 37-69, 2000.

[40] M. Probst, H. Deutsch, K. Becker, T.D. Märk, "Calculations of absolute electron impact ionization cross sections for molecules of technological relevance using the DM formalism," International Journal of Mass Spectrometry, vol. 206, pp. 13-15, 2001.

[41] H. Deutsch, K. Becker, R. Basner, M. Schmidt, T.D. Märk, "Application of the modified additivity rule for the calculation of electron-impact ionization cross section of complex molecules," Journal of Physical Chemistry A, vol. 102, pp. 8819-8826, 1998.

[42] W. Hwang, Y.-K. Kim, "New model for electron-impact ionization cross sections of molecules," Journal of Chemical Physics, vol. 104, pp. 2956-2966, 1996

[43] H. Deutsch, K. Hilpert, K. Becker, M. Probst, and T.D. Märk, "Calculated absolute electron-impact ionization cross sections for AlO, Al2O, and WOx (x = 1-3)," Journal of Applied Physics, vol. 89, pp. 1915-1921, 2001.

[44] V.S. Yungman, V.A. Medvedev, I.V. Veits, and G.A. Bergman, IVTANTHERMO - A Thermodynamic Database and Software System for the Personal Computer, CRC Press and Begell House: Boca Raton, 1993.

[45] O. Knacke, O. Kubaschewski, and K. Hesselmann, Thermochemical properties of inorganic substances II, $2^{\text {nd }}$ ed., Springer: Berlin, 1991.
[46] I. Barin, O. Knacke, and O. Kubaschewski, Thermochemical properties of inorganic substances, Springer: Berlin, 1977.

[47] D. Figgen, W. Müller, M. Schweizer, H. Stoll, K.A. Peterson, "Atomization energies and enthalpies of formation of the SnBin ( $\mathrm{n}=1-3)$ gaseous molecules by Knudsen cell Mass Spectrometry," Journal of Chemical Physics, vol. 118, pp. 4766-4767, 2003.

[48] O. Kubaschewski, C.B. Alcock, and P.J. Spencer, Materials thermochemistry, $6^{\text {th }}$ ed. Pergamon Press Ltd: Oxford, England, 1993.

[49] P.K. Raychaudhuri and F.E. Stafford, "Alloy thermodynamics by Mass Spectrometry: a critical review," Materials Science and Engineering, vol. 20, pp. 1-18, 1975.

[50] L.N. Sidorov and M.V. Korobov, "Mass spectrometric determination of activity in molten salt mixtures," Shitsuryo Bunseki, vol. 29, pp. 199-219, 1981.

[51] A.P. Lyubimov, V.Ya. Zobens, V.I. Rakhovski, "A mass spectrometric determination of the thermodynamic characteristics of binary metallic systems," Zhurnal Fizicheskoi Khimii, vol. 32, pp. 1804, 1958.

[52] G.R. Belton, R.J. Fruehan, "The determination of activities by Mass Spectrometry. I: the liquid metallic system Iron-Nickel and Iron-Cobalt," Journal of Physical Chemistry, vol. 71, pp. 1403$1409,1967$.

[53] A. Neckel and S. Wagner, "Massenspektrometrische bestimmung thermodynamischer aktivitaeten. I: das system Gold-Kupfer," Berichte der Bunsen-Gesellschaft für Physikalische Chemie, vol. 73, pp. 210, 1969.

[54] J. Kapala, D. Kath, K. Hilpert, "Thermodynamic activities and phase boundaries for the alloys of the Ni3Al-Ni3Ti pseudobinary section in the Ni-Al-Ti system," Metallurgical Transactions A, 27A, 2673-2677, 1996.

[55] A. Popovic, B. Malic, L. Bencze, "Knudsen cell mass spectrometric investigation of the PbO-ZrO2-TiO2System," Rapid Communications in Mass Spectrometry, vol. 13, pp. 1129-1137, 1999.

[56] V. Venugopal, S.G. Kulkarni, A.A. Banerjee, G.A. Rama Rao, K.N. Roy, D.D. Sood, "Determination of partial pressures of Te, $\mathrm{Te} 2, \mathrm{Ag}, \mathrm{Ag} 2, \mathrm{AgTe}$ and $\mathrm{Ag} 2 \mathrm{Te}$ gaseous species over $\mathrm{Ag}(\mathrm{s})+$ $\mathrm{Ag} 2 \mathrm{Te}(\mathrm{s})$ system," Journal of Nuclear Materials, vol. 238, pp. 218223, 1996.

[57] R. Viswanathan, M. Sai Baba, T.S. Lakshmi Narasimhan, R. Balasubramanian, D. Darwin Albert Raj, C.K. Mathews, "Homogeneity ranges and thermodynamic properties of the Te-rich phases in the Cr-Te system," Journal of Alloys and Compounds, vol. 206, pp. 201-210, 1994. [Physical Abstract].

[58] K.N. Marushkin, G.D. Nipan, V.B. Lazarev, "Thermodynamics and $(\mathrm{p}, \mathrm{T}, \mathrm{x})$ phase diagram of (Barium oxide + Diyttrium trioxide)," The Journal of Chemical Thermodynamics, vol. 27, pp. 465474,1995.

[59] L. Bencze, K. Hilpert, "Thermochemistry of the Ni-Hf system intermetallic phases," Metallurgical Transactions A, vol. 27A, pp. 3576-3590, 1996.

[60] K. Hilpert, M. Albers, D. Kath, "Vaporization studies of Nickel and Titanium Aluminides," In: Structural Intermetallics, M.V. Nathal, R. Darolia, C.T. Liu, P.L. Martin, D.B. Miracle, R. Wagner, and M. Yamaguchi, Eds., The Minerals, Metals \& Materials Society, 1997.

[61] W. Kuncewicz-Kupczyk, D. Kobertz, M. Miller, Ch. Chatillon, L. Singheiser, K. Hilpert, "Vaporization studies of the $\mathrm{La}_{2} \mathrm{O}_{3}-\mathrm{Ga}_{2} \mathrm{O}_{3}$ system," Journal of the American Ceramic Society, vol. 85, pp. 2299-2305, 2002,

[62] S.I. Lopatin, "Paroobrazovan'ie w fosfatnichsist'emach," $Z h$ Obschch Khim, vol. 67, pp. 208-227, 1997.

[63] A.I. Zaitsev, A.D. Litvina, B.M. Mogutnov, "Thermodynamics of $\mathrm{Na}_{2} \mathrm{O}-\mathrm{SiO}_{2}$ melts," Inorganic Materials, vol. 33, pp. 1265-1273, 1997. 